\title{
Guardianes del Honor: los guardias civiles y la historia de su institución durante la Segunda República*
}

Foster Chamberlin

\section{Boğaziçi University}

fosterpchambers@gmail.com

\section{Fecha recepción 15.05.2017 / Fecha aceptación 29.11.2017}

\section{Resumen}

La Guardia Civil forma parte esencial de la violencia política de la Segunda República, y quienes más han escrito sobre este tema han sido miembros de la propia institución dispuestos a defender su honor. En este artículo analizaré cómo estos historiadores han retratado en libros y revistas de historia desde 1968 hasta la actualidad, una serie de incidentes violentos específicos que se produjeron durante el periodo republicano. De este modo, demostraré que incluso cuando España modificó su concepción del modelo policial durante la Tran-

\begin{abstract}
The Civil Guard is an essential part of the story of the political violence that plagued the Second Republic, and its history has largely been written by members of the institution itself eagerly defending its honour. This article traces how specific incidences of violence during the Second Republic were portrayed by Civil Guard historians in books and history magazine articles from 1968 to the present, and in so doing it will demonstrate that, even as Spain shifted from a public order to a citizen security model of policing
\end{abstract}

\footnotetext{
* Me gustaría dar las gracias a Irene Olivares y Juan Ortiz por su ayuda en la recuperación de documentos, y a Elena Blanco Suarez, Eduardo González Calleja, David Henderson, Judith Hughes, Pamela Radcliff y Elizabeth Schwall por sus comentarios y ediciones. Mi gratitud especial a Miguel López Corral por aceptar ser entrevistado para este artículo y a Pilar Mera Costas por la traducción del mismo.
} 
sición, avanzando desde la idea de orden público a la de seguridad ciudadana, estos historiadores tenían tan interiorizada la visión franquista de una Guardia Civil que había ganado su honor gracias a su lucha desapasionada contra el desorden de la Segunda República, que sólo la nueva generación formada durante la Transición fue capaz de elaborar una nueva narrativa que presentaba al cuerpo como servidor del interés público. Aún así, el deseo inquebrantable de defender el honor de la institución ha hecho que esta nueva generación también represente el cuerpo como un ente apolítico.

\section{Palabras clave}

Guardia Civil, Transición, orden público, seguridad ciudadana, violencia política, militarización during the Transition, these historians remained trapped by a Francoist vision of the Civil Guard gaining honour through dispassionately fighting the disorder of the Second Republic. The vision was so engrained that only a new generation trained after the Transition was able to find a new narrative that portrayed the Civil Guard as serving the interests of the public. Still, the unwavering desire to uphold the honour of the institution has meant that this new generation also depicts the corps as apolitical.

\section{Key words}

Civil Guard, Transition, public order, citizen security, political violence, militarization 


\section{Introducción}

La Guardia Civil es un cuerpo de seguridad de naturaleza militar que se formó en $1844^{1}$. Su fundador, un aristócrata de sangre azul conocido como el Duque de Ahumada, escribió en 1845 la Cartilla del Guardia Civil, un libro que recoge las normas que definen la misión del guardia civil y rigen su vida diaria. Los guardias civiles memorizan la Cartilla y llevan una copia encima en todo momento ${ }^{2}$. Su primer párrafo dice: «el Honor es la principal divisa del Guardia Civil; debe, por consiguiente, conservarse sin mancha. Una vez perdido no se recobra jamás»"3. El trabajo de Ahumada ha demostrado ser un documento perdurable — sigue vigente en la actualidad - y el mantenimiento del honor se ha convertido en el lema y guía principal de la Guardia Civil. A pesar de que el Duque no define de manera explícita lo que entiende por honor, deja claro su idea sobre él cuando insiste en la importancia de mantener el respeto de los ciudadanos ${ }^{4}$. En consecuencia, los guardias civiles siempre se han preocupado por su imagen pública y han sentido la necesidad de defender sus acciones frente a las críticas, mostrándose poco receptivos a ellas, pues cualquier admisión de culpa podría significar una pérdida irrecuperable de honor. Y las críticas no han sido escasas. Los partidos de izquierda, desde los progresistas del siglo XIX a los socialistas de la Segunda República y la Transición, han denunciado reiteradamente que la Guardia Civil tiene un sesgo conservador, utiliza técnicas brutales y muestra poco respeto por los derechos de los ciudadanos. El orde-

1. Sobre la decisión de convertir la Guardia Civil en una institución militar, véase D. López Garrido, $L a$ Guardia Civil y los orígenes del Estado centralista, Barcelona, 1982.

2.G. Blaney, Jr., "The Civil Guard and the Spanish Second Republic 1931-1936", Tesis Doctoral, University of London, 2007, 37.

3. Cartilla del Guardia Civil. Madrid, 1846, 11.

4. Cartilla... op. cit., 192-93. B. Wyatt-Brown también hace hincapié en que un componente crítico de honor es que "los juicios de comportamiento son ratificados por consenso de la comunidad". Southern Honor: Ethics and Behavior in the Old South, New York, 1982, xv. 
namiento jurídico español reforzó esta animosidad al considerar un delito los insultos a las Fuerzas Armadas, incluida la Guardia Civil.

Sin embargo, los guardias civiles también entendieron que preservar la neutralidad política era una cuestión importante para mantener el honor de su institución. Como una organización burocrática del Estado, la Guardia Civil sirve a cualquier gobierno que esté en el poder y no a una ideología, régimen o partido concretos. De acuerdo con su condición militar, los guardias civiles consideraron que su deber era seguir las órdenes de las autoridades militares y civiles, y nada más. Se autopercibían por encima de luchas políticas y se les prohibió unirse a cualquier partido. Los sucesivos gobiernos alentaron este tipo de pensamiento con el objetivo de poner fin a las políticas pretorianas que se habían dado en España durante largos periodos ${ }^{5}$. Aún así, ha resultado difícil para la Guardia Civil mantener esta neutralidad política, puesto que la mayor parte de las críticas que recibe la institución han venido siempre de la izquierda.

Prácticamente desde la fundación del cuerpo, los guardias civiles, en activo o retirados, han intentado proteger su honor tal y como ellos lo entienden, escribiendo historias positivas de su institución ${ }^{6}$. En este artículo, examinaré desde una perspectiva externa una muestra representativa de estos escritos sobre la Guardia Civil durante la Segunda República elaborados desde su interior y mencionaré otras obras sobre la institución en esta época también. La República quizás sea la etapa sobre la que prefieren escribir los historiadores de la Guardia Civil tras el momento de su fundación, ya que, desde su punto de vista, tienen que contar las numerosas condecoraciones que los guardias civiles ganaron en su lucha contra el desorden durante este periodo. Además, como el grado de violencia política de la época permitía a quienes acusaban a la institución de brutalidad encontrar numerosas evidencias en las que apoyar sus argumentos, los historiadores de la Guardia Civil sintieron que debían refutar dichas acusaciones. En este artículo abordaré cómo los guardias civiles adaptaron sus estrategias para mantener el honor de su institución a través del relato de su historia teniendo en cuenta el contexto de una sociedad española que va cambiado su manera de entender la actividad policial desde 1968 hasta nuestros días. La decisión de comenzar en 1968 se justifica por el aumento notable de textos de historiadores de la Guardia Civil que se produjo ese año, debido a la fundación de la Revista de Estudios Históricos de la Guardia Civil, una reacción a las crecientes críticas al cuerpo. A partir de ese momento, se pueden distinguir tres etapas en sus escritos. ${ }^{7}$ En la primera, que va desde 1968 hasta 1977, mantienen el discurso franquista respecto a la Segunda República, es decir, la retratan como un período de creciente violencia política y en el que el poder del comunismo va en aumento. Esto les permite presentar su institución como una heroica defensora del orden en un momento de peligrosos disturbios. Sin embargo, en la etapa posterior, entre 1978 y 1988, se produjo en España un cambio en

5. Para más información sobre pretorianismo, véase C.P. Boyd, "Violencia pretoriana: del Cu-Cut! Al 23F”, en S. Juliá (Dir.), Violencia política en la Espña del siglo XX, Madrid, 2000, 289-325.

6. G. Blaney, Jr., "La historiografía sobre la Guardia Civil. Crítica y propuestas de investigación”, Política y Sociedad, 42, 2005, 33.

7. Correo electrónico de Miguel López Corral al autor. 18 de noviembre de 2014. 
la percepción del papel de la policía, que pasa de ser la encargada de mantener el orden público a encargarse de proteger a los ciudadanos. Pese a ello, y aun cayendo en un lenguaje abiertamente franquista, los historiadores de la Guardia Civil continuaron caracterizando a los guardias civiles como los defensores del orden en el caos de la República. Las historias de la Guardia Civil sobre este periodo no vivieron una transición hacia un enfoque más neutral hasta que surgió una nueva generación formada en la democracia que entendió que la función de la Guardia Civil era garantizar la seguridad ciudadana. Al preocuparse también por el público y no sólo por el Estado, esta nueva generación ha pasado a dirigirse a una audiencia popular y académica además de a su público interno. Sin embargo, estos nuevos historiadores siguen identificándose con la naturaleza militar de la Guardia Civil y su comprensión particular del honor, por lo que mantienen su visión de la institución como un actor apolítico.

\section{El discurso franquista (1968-1977)}

Antes de 1968 apenas se había escrito nada específico sobre la Guardia Civil durante la Segunda República ${ }^{8}$, y muy poco sobre la Guardia Civil en general. Durante los primeros años de la dictadura de Franco, los guardias civiles no sintieron la necesidad de escribir su historia como una forma de defender su honor, pues ya tenían una posición privilegiada dentro del régimen ${ }^{9}$. Sin embargo, durante la década de los sesenta, la dictadura empezó a permitir cierto nivel de crítica al gobierno, incluyendo la Guardia Civil. También hubo un aumento de la oposición ilegal. Como escribe Kostis Kornetis, «desde 1967-1968 en adelante, los enfrentamientos fueron más allá de los campus universitarios y las disputas internas de los estudiantes. Los enfrentamientos con la policía se convirtieron en un fenómeno común y podían desencadenarse por asuntos cotidianos, como la organización de una asamblea sin permiso» ${ }^{10}$. Los guardias civiles también eran conscientes de que su honor ya sufría ataques por parte de historiadores extranjeros que trabajaban sobre España. En 1967, un artículo de la revista profesional Guardia Civil se lamentaba de que el tricornio fuese todavía "el símbolo de una "leyenda negra"» entre extranjeros y gitanos; aunque alegaba que «entre los propios españoles, el terror que al principio inspiraban los "tricornios" comienza a transformarse en respeto y admiración»" ${ }^{11}$. Mientras, escritores ex-

8. El periodista franquista Eduardo Comín Colomer publicó De Castilblanco a Casas Viejas en 1959.

9. S. Payne, Politics and the Military in Modern Spain, Oxford, 1967, 448. La posición de la Guardia Civil mejoró bajo el régimen de Franco a pesar de que en un principio se había planteado su disolución. M. López Corral, La Guardia Civil: Claves históricas para entender a la Benemérita y a sus hombres (1844-1975), Madrid, 2009, 391-96.

10. K. Kornetis, "Spain and Greece”, en M. Klimke y J. Scharloth, (Dirs.), 1968 in Europe: A History of Protest and Activisim, 1956-1977, Nueva York, 2008, 257.

11. V. Cardoso, "La Guardia Civil: Fin de una leyenda negra", Guardia Civil, 24, 1967, 3. 
tranjeros como Gerald Brenan caracterizaban la Guardia Civil como una fuerza brutal y represiva que «no pudo mantener el dedo fuera del gatillo» ${ }^{12}$.

En este contexto de emergentes amenazas extranjeras y nacionales para el honor de su institución, los guardias civiles comenzaron a escribir su propia historia del cuerpo, una historia que buscaba demostrar que su conducta había sido honorable ${ }^{13}$. Con este objetivo, en 1968, el teniente coronel Francisco Aguado Sánchez fundó la Revista de Estudios Históricos de la Guardia Civil (REHGC) $)^{14}$, una publicación bianual que contenía una media docena de artículos sobre la Benemérita, cuya extensión estaba entre las veinte y las cincuenta páginas. Aunque ocasionalmente se publicaban contribuciones externas ${ }^{15}$, la gran mayoría de los textos de la revista eran obra de un pequeño círculo de guardias civiles historiadores. Casi todos llevaban unas pocas notas a pie de página con referencia a un pequeño número de fuentes secundarias, aunque también citaban algunas fuentes primarias, principalmente del archivo interno de la Guardia Civil. El objetivo explícito de la publicación era aumentar el conocimiento público de «nuestras glorias» ${ }^{16}$, pero, dado que los artículos eran de naturaleza altamente especializada, que se centraban casi exclusivamente en la Guardia Civil y que fueron escritos principalmente por miembros del cuerpo, es presumible que fuera de él la revista solo llegó a una pequeña audiencia de entusiastas de la historia militar. Por el contrario, su difusión interna era muy elevada, puesto que la suscripción a la revista era obligatoria para todos los oficiales de la Guardia Civil ${ }^{17}$.

Para comprender cómo los escritores de la REHGC concebían su trabajo como historiadores, es necesario entender en qué consistía la hoja de servicios, un documento referido a cada guardia civil en el que aparecen sus datos personales, promociones, destinos, así como las distinciones o castigos recibidos. Este documento conservaba de manera oficial, un registro de sus logros, incluido todo el honor ganado o perdido. Ese honor individual se podía calcular con precisión sumando el número y el prestigio de los premios ganados y restando las faltas. Como indica Julian Pitt-Rivers, "la importancia de los actos de honor público y la concesión de dignidades está, por lo tanto, en esto: conceden el sello de reconocimiento público a reputaciones que, de otro modo, quedarían en duda, dotándolas de permanencia"18. En este caso, el reconocimiento no fue ganado por el individuo sólo para sí mismo, sino también para la Guardia Civil en su conjunto. Al escribir la historia de su institución, los guardias civiles

12. G. Brenan, The Spanish Labyrinth: An Account of the Social and Political Background of the Civil War, Cambridge, 1990, 157.

13. Blaney, "La historiografía...”, op. cit., 33.

14. Blaney, "La historiografía..., op. cit., 33, correo electrónico de Miguel López Corral al autor, 18 de noviembre de 2014.

15. A pesar de que algunos escritores no eran guardias civiles, se tienen en cuenta, porque escribieron para esta revista de historia semioficial de la Guardia Civil.

16. El General Presidente de la Comisión Directiva de Estudios Históricos, "Justificación”, REHGC, 1, 1968.

17. Correo electrónico de Miguel López Corral al autor, 18 de noviembre de 2014.

18. J. Pitt-Rivers, "Honor", en D.L. Sills (Dir.), International Encyclopedia of the Social Sciences, 6a ed., Nueva York 1968, 504. 
intentaron contribuir a este proceso de mejora de honor a través del reconocimiento público. Su trabajo consistía en crear una especie de hoja de servicios de la Guardia Civil, catalogando las vicisitudes de sus cambios de organización y recopilando aquellos hechos individuales que incrementasen el honor del cuerpo en su conjunto. Para que los registros de honor que se conservaban en las hojas de servicio y otros documentos internos contribuyesen a aumentar la estima de la Guardia Civil en la sociedad en general, esta información tenía que ser llevada a un público más amplio ${ }^{19}$. Por contra, la vida diaria del guardia civil medio no preocupaba en absoluto a estos historiadores, ya que no añadía nada al recuento de méritos. Pero el temor de los escritores a la pérdida de honor implicaba que la ecuación no se ejecutaba a la inversa. Cualquier acción deshonrosa que no se podía explicar se despachaba como un caso aislado que no era representativo de la institución en su conjunto. Por supuesto, los casos de valentía o sacrificio excepcional sí se consideraban representativos. Por ejemplo, en 1970 la REHGC publicó un artículo sobre los sucesos de Castilblanco, un incidente en el que cuatro guardias civiles fueron asesinados durante una huelga en este pequeño pueblo de Badajoz. El texto mostraba a los guardias civiles solicitando que se disolviese la protesta «con el fusil colgado de un hombro» ${ }^{20}$. Pero la multitud respondió a su petición pacífica atacándolos y asesinándolos brutalmente con pistolas, piedras, gruesos palos y zapatos ${ }^{21}$. Durante la semana que siguió a los hechos de Castilblanco, los guardias civiles mataron a varios manifestantes en otros seis incidentes ${ }^{22}$. El más destacado ocurrió en la localidad de Arnedo (Logroño), donde se registraron once muertos, entre ellos cuatro mujeres y un niño de dos años de edad ${ }^{23}$. La REHGC jamás publicó un artículo sobre ninguno de estos sucesos.

La REHGC publicaba con frecuencia artículos sobre la Segunda República que sistemáticamente representaban a la Guardia Civil y a los rebeldes nacionales de 1936 como valientes defensores del orden público en una época de caos; aunque, no eran acusaciones directas contra este régimen, sin duda porque los autores pensaron que un ataque de ese tipo desde su revista de historia semioficial socavaría el carácter apolítico de la Guardia Civil. El coronel Antonio Díaz Carmona, autor de dos artículos de la REHGC sobre el intento de golpe de Estado del mes de agosto de 1932, afirmaba explícitamente que iba a corregir la visión que mostraba a la República como un régimen estable ${ }^{24}$, y alegaba que una de las razones por las que el general Sanjurjo se había rebelado contra el gobierno era que «nunca fueron sacrifi-

19. Por ejemplo, A. Díaz Carmona, "El 10 de agosto de 1932 (y II).-_Sanjurjo en Sevilla”, REHGC, 2, 1968, 111-38 copia básicamente toda la hoja de servicios del general Sanjurjo para contrarrestar los juicios que lo calificaban de ligero e impulsivo.

20. E. Rodríguez Castaños, "Castilblanco, un drama en la República”, REHGC, 3, 1970, 156.

21. Rodríguez Castaños, “Castilblanco...”, op. cit., 157.

22. Una lista completa de estos incidentes, en F. Aguado Sánchez, La historia de la Guardia Civil, Madrid, 1984, IV, 277.

23. Un relato minucioso de los sucesos de Arnedo, incluido el papel de la Guardia Civil en ellos, en C. Gil Andrés, La República en la plaza: los sucesos de Arnedo de 1932, Logroño, 2002.

24. A. Díaz Carmona, "El 10 de agosto de 1932. I.-Un General romántico y una Patria que se hunde", REHGC, 1, 1968, 59. El autor, que en aquel momento era teniente, tuvo un papel destacado en el golpe de Estado de 1932. 
cados en nuestro ámbito nacional tantos obreros, tantos guardias civiles, guardias de asalto, policías y soldados, como en la época de la República» ${ }^{25}$. Según Díaz Carmona, Sanjurjo también estaba preocupado porque «el comunismo ya se ha dejado ver. Moscú se atribuye la quema de los conventos, asaltos y saqueos» ${ }^{26}$. Definir la Segunda República como un régimen comunista y producto de la intromisión extranjera era una de las tácticas favoritas del tardo-franquismo ${ }^{27}$. Irónicamente, Díaz Carmona también insinuaba que la República no era realmente una democracia. Así, escribía que la Ley de Defensa de la República, que definía diversos actos de agresión a la República y estados de excepción, tenía un carácter dictatorial y que Castilblanco había sido «quizás punto de partida de quienes ya comenzaron a ver que la República estaba muy lejos de encauzarse dentro de un orden democrático» ${ }^{28}$. Tales acusaciones también fueron típicas durante el tardo-franquismo, momento en el que el régimen trató de restar importancia a su propia naturaleza dictatorial ${ }^{29}$. Sin embargo, pese a señalar que el desorden y la falta de democracia habían sido los motivos de Sanjurjo para levantarse contra el gobierno de Azaña, para Díaz Carmona el general no incumplió su obligación de ser objetivo para ser honorable. Una idea que justificaba afirmando que había sido «totalmente objetivo» en su evaluación sobre lo que era mejor para su país. ${ }^{30}$.

El incidente favorito de los historiadores de la Guardia Civil para representar a los miembros de su institución como héroes dispuestos a sacrificar sus vidas en nombre del orden público es la insurrección socialista de octubre de $1934^{31}$, pues fue el momento, antes del intento de golpe de Estado de julio de 1936, en el que se enfrentaron a su mayor desafío y obtuvieron su mayor cuota de honor ${ }^{32}$. En sus primeros años, la REHGC publicó dos artículos sobre la rebelión ${ }^{33}$, y Aguado Sánchez, autor de uno de ellos, escribió dos versiones de un libro sobre el mismo tema en $1972^{34}$. Para Aguado Sánchez en particular, la Guardia Civil fue la protagonista de la sublevación. Este historiador catalogó todos los incidentes en los que los guardias civiles habían estado involucrados y elaboró una tabla con el número preciso de

25. Díaz Carmona, “El 10 de agosto...”, op. cit., 79.

26. Díaz Carmona, "El 10 de agosto...”, op. cit., 80.

27. M.-C. Chaput, "Commémorations et images de la Seconde République dans trois quotidiens: $A B C$, La Vanguardia, Madrid (1946-1976)”, en M.-C. Chaput y T. Gómez (Dirs.), Histoire et mémoire de la Seconde République espagnole: Hommage à Jacques Maurice, Nanterre, 2002, 404-05.

28. A. Díaz Carmona, "El 10 de agosto de 1932 (y II).-CSanjurjo en Sevilla”, REHGC, 2, 1969, 80, 114.

29. Chaput, "Commémorations..., op. cit., 405.

30. Díaz Carmona, "El 10 de agosto..., op. cit., 76.

31. Véase, por ejemplo, M. Luengo Muñoz, "Revolución en Asturias de 1934: El Combate de Campomanes”, REHGC, 1, 1968, 33.

32. Los guardias civiles ganaron una Cruz Laureada de San Fernando y dos Medallas Militares por su lucha contra la insurrección. F. Aguado Sánchez, La revolución de octubre de 1934, Madrid, 1972, 508.

33. Luengo Muñoz "Revolución...”, op. cit., 1968, F. Aguado Sánchez, "La Guardia Civil en la Segunda República. -Antecedentes históricos de la revolución roja de octubre de 1934”, REHGC, 4, 1971.

34. F. Aguado Sánchez, La Guardia Civil en la Revolución Roja de octubre de 1934, Madrid, 1972, Aguado Sánchez, La Revolución... op. cit. 
bajas que había sufrido el cuerpo ${ }^{35}$. Creía que el sacrificio de cada uno debía ser recordado. Así, singularizó los casos del capitán José Alonso Nart y el teniente Fernando Halcón Lucas, condecorados con sendas medallas por su valor, como ejemplos «del más puro heroísmo» de la Guardia Civil ${ }^{36}$. Sus medallas eran una prueba del honor ganado para la institución, y se esperaba que sirviese de inspiración para que futuros guardias civiles acumulasen nuevas glorias. Más problemáticos eran casos como el del teniente Gabriel Torrens Llompart, quien había rendido fácilmente el puesto que estaba bajo sus órdenes a los rebeldes y luego había colaborado con ellos. Aguado Sánchez censuraba que Torrens no hubiese tomado «ninguna medida para salvar su honor ${ }^{37}$, pero como guardia civil también hizo su propio esfuerzo para mostrarse objetivo al analizar el comportamiento de este. Por ello afirmaba que trataría de comprender «el porqué de su conducta, tan censurable como bochornosa $»^{38}$. Otro guardia civil cuya conducta en la represión de la sublevación resultaba cuestionable era el comandante Lisardo Doval Bravo. Había liderado los trabajos para capturar a los cabecillas rebeldes y descubrir sus depósitos de armas, pero fue despedido por las numerosas acusaciones de tortura e incluso asesinato en el desempeño de su misión. Aguado Sánchez eligió retratar a Doval simplemente como un excelente detective. En cuanto a las denuncias en su contra, las descartó, reduciéndolas a una campaña subversiva orquestada cuidadosamente desde fuera de España ${ }^{39}$. Una vez más, fuerzas extranjeras amenazaban con socavar el honor de la Guardia Civil y con ello la estabilidad de la patria.

La historia de la revolución de octubre del 34 no solo era importante para defender el honor de la Guardia Civil, también resultaba una parte crucial de la autojustificación del régimen franquista. Esta sublevación demostraba que había una fuerte amenaza contra el orden público por parte de la izquierda que Franco había conseguido controlar ${ }^{40}$. La clave de este argumento era mostrar el levantamiento como un intento de revolución comunista provocado por elementos extranjeros. Eso hizo Aguado Sánchez, cuyo libro comienza con un prólogo del teniente general Luis Díez-Alegría Gutiérrez, ex Director General de la Guardia Civil, que lo enmarca en términos claramente franquistas al describir octubre 1934 como «una revolución del más puro estilo marxista que convirtiese a España en una república soviética sometida a las directrices del Kremlin ${ }^{41}$. Sin embargo, es evidente que el público general ya se estaba volviendo escéptico con esta interpretación de la revuelta. En 1972, el

35. Aguado Sánchez, La Revolución... op. cit., 17.

36. Aguado Sánchez, La Revolución... op. cit., 13.

37. Aguado Sánchez, La Revolución... op. cit., 140.

38. Aguado Sánchez, La Revolución... op. cit., 139.

39. Aguado Sánchez, La Revolución... op. cit., 319.

40. De hecho, la Segunda República en general era el ejemplo favorito del régimen franquista de por qué los españoles «eran intrínsecamente incapaces de vivir bajo un régimen democrático sin recurrir a la violencia». C. Humlebæk, "La memoria de la Segunda República durante la transición a la democracia”, en Á. Egido León (Dir.), Memoria de la Segunda República: mito y realidad, Madrid, 2006, 164.

41. Aguado Sánchez, La Revolución... op. cit., 11. Después de su prólogo bastante explícito desde el punto de vista político, el cuerpo del libro de Aguado Sánchez ofrece un catálogo de los acontecimientos de octubre de 1934, al igual que sus artículos en la REHGC. 
Servicio de Estudios Históricos de la Guardia Civil publicó una versión de la obra de Aguado Sánchez titulada La Guardia Civil en la Revolución Roja de octubre de 1934, pero ese mismo año la Editorial San Martín, empresa privada, retiró la palabra roja del título del libro. Probablemente la Editorial San Martín quería dirigirse a un público más amplio que ya no quería leer sobre octubre de 1934 como una revolución roja.

En otro libro del historiador y teniente de la Guardia Civil, Fernando Rivas Gómez, titulado El Frente Popular: antecedentes de un alzamiento, se siguió el mismo patrón, aunque en esta ocasión fue Aguado Sánchez quien escribió el prólogo ${ }^{42}$. Junto a la revuelta de octubre 1934, el período del Frente Popular era la clave para la justificación histórica que el franquismo hacía de sí mismo. Si de febrero a julio de 1936 se había vivido una etapa de violencia política y revolución en espiral creciente y fuera de control, entonces el levantamiento nacionalista había sido necesario para restablecer el orden. Rivas reforzó esta narrativa realizando un catálogo exhaustivo de los incidentes de violencia política que se sucedieron bajo el gobierno del Frente Popular ${ }^{43}$. A pesar de que su título sugiere que el libro está dedicado al Frente Popular en general, su atención se centra mayoritariamente en los problemas de orden público, y la Guardia Civil es, naturalmente, la protagonista central de la historia. En los muchos incidentes de violencia de ida y vuelta descritos en el libro, la izquierda es siempre la instigadora. Aguado Sánchez lo dejaba claro en su prólogo, donde elogiaba el «inevitable y más que justificado Glorioso Alzamiento Nacional» ${ }^{44}$, que había restaurado «el orden público, meta sublime y moral de todo buen gobernante» ${ }^{45}$.

Mientras Rivas consideraba a la mayoría de los guardias civiles como luchadores por el orden, incluso antes de que hubiese comenzado la guerra civil, todavía tenía que enfrentarse a los miembros de la institución que no habían actuado de un modo honorable. Con respecto a las acusaciones en contra del comandante Doval, las descartaba porque carecía de pruebas y sostenía que sin evidencias nadie sabía realmente lo que sus hombres habían hecho o no ${ }^{46}$. Rivas tampoco pudo evitar hablar del capitán de la Guardia Civil Fernando Condés Romero, quien dirigió el grupo que asesinó a José Calvo Sotelo. Hábilmente evitó que Condés manchase el honor del cuerpo con el argumento de que el capitán había sido recomisionado en la Guardia Civil y que aún no había recibido su cargo, destino, carnet o uniforme; aunque, «bajo ningún concepto es posible considerar que representaba al Cuerpo de la Guardia Civil» ${ }^{47}$. Al mismo tiempo, Rivas parecía creer que como guardia civil, Condés no podía haber sido malo del todo. Así, relataba que Condés había tenido un momento de duda durante el secuestro de Calvo Sotelo y sugería que «su reciente reingreso en la Guardia Civil puede malograrse. Ha practicado una detención ilegal y un registro a deshora y sin autorización judicial. . . Pero

42. F. Rivas, El Frente Popular: antecedentes de un alzamiento, Madrid, 1976.

43. F. Rivas Gómez, "La República en marcha”, REHGC, 9-10, 1976-77 es también en gran parte una lista de incidentes de violencia política durante la Segunda República.

44. Rivas, El Frente... op. cit., 11.

45. Rivas, El Frente... op. cit., 12.

46. Rivas, El Frente... op. cit., 96-97.

47. Rivas, El Frente ... op. cit., 371. 
Condés, que no es ningún cobarde, se sobrepone a sus dudas y temores"48. Rivas no podía menos que admirar su firmeza y su coraje; mientras que, Aguado Sánchez no pudo encontrar ninguna esperanza de redención en lo que vio como la rendición cobarde de Torrens.

\section{Vieja Guardia, nuevo lenguaje (1978-1988)}

Tras la muerte de Franco, los cambios en las fuerzas de policía se materializaron lentamente en un principio, pero en 1978, España tenía una nueva constitución y con ella, la Guardia Civil, una nueva definición de su misión ${ }^{49}$. Desde su fundación, su Reglamento había señalado que el objeto del cuerpo era la conservación del orden público ${ }^{50}$. Eduardo González Calleja explica que el orden público se entendía como «un estado de hecho y de derecho opuesto al desorden ${ }^{51}$. En otras palabras, el concepto se definía en términos negativos simplemente como la ausencia de trastornos. Sin embargo, durante la Transición la idea de seguridad ciudadana emergió como una concepción alternativa al papel de fuerza policial que la Guardia Civil debía desempeñar. González Calleja define el término como «una actitud de salvaguardia propia de una sociedad democrática, en la que las personas pueden ejercer sus derechos y libertades sin más cortapisas que las establecidas en las leyes» ${ }^{52}$. El modelo de seguridad ciudadana concibe las fuerzas policiales tomando un papel positivo en la garantía de los derechos de los ciudadanos en lugar de limitarse a reprimir el desorden. El público general y la élite política aceptaron este nuevo concepto con rapidez y se incorporó al Artículo 104 de la Constitución de $1978^{53}$. Sin embargo, como explica Robert C. Hudson, «en los cuatro años posteriores a la muerte de Franco, las distintas fuerzas policiales fueron cambiando muy lentamente sus métodos» ${ }^{54}$. No fue hasta el fallido golpe de estado derechista de 1981, en el que participaron algunos guardias civiles, que «en última instancia, aseguró la desaparición del franquismo y, a su vez condujo a la introducción de reformas de la policía» ${ }^{55}$.

48. Rivas, El Frente... op. cit., 376.

49. Rivas, El Frente... op. cit. es un ejemplo de la mentalidad franquista que permanecía en de las fuerzas de orden público inmediatamente después de la muerte de Franco. M.J. Izu Belloso, "Los conceptos de orden público y seguridad ciudadana tras la Constitución de 1978”, Revista Española de Derecho Administrativo, 1988, 1.

50. Contestaciones completas del "Instituto Reus" para el ingreso en el Cuerpo de la Guardia Civil, Madrid, $1935,115$.

51. E. González Calleja, En nombre de la autoridad: La defensa del orden público durante la Segunda República Española (1931-1936), Granada, 2014, 3.

52. González Calleja, El nombre... op. cit., 6.

53. F. Carrillo y M. Álamo, Los guardias civiles: Esos ciudadanos uniformados, Alzira, 2001, 30-32. El artículo 104 dice «1. Las Fuerzas y Cuerpos de seguridad, bajo la dependencia del Gobierno, tendrán como misión proteger el libre ejercicio de los derechos y libertades y garantizar la seguridad ciudadana». C. Chincilla Marín, Legislación sobre Fuerzas y Cuerpos de Seguridad. Madrid, 1986, 24.

54. R.C. Hudson, "Democracy and the Spanish Police Forces since 1975”, Police Journal, 61, 1988, 54.

55. Hudson, “Democracy...”, op. cit., 54. 
Aunque eliminó el lenguaje abiertamente franquista de su trabajo, el mismo grupo de historiadores de la Guardia Civil que había estado escribiendo desde finales de los 60 utilizó la historia para luchar contra la idea de alejar la misión de su institución del orden público. El artículo «La Seguridad pública en el periodo constitucional», publicado en el segundo número de 1982 de la $R E H G C$, exponía su posición. La tesis de los autores era que la «inseguridad ha sido la causa principal de la frustración de casi todas las constituciones» ${ }^{56}$. El disgusto de los historiadores de la Guardia Civil con la Segunda República se mantuvo también después de la muerte de Franco. En ese artículo de 1982 sobre la República, escrito por Fernando Rivas y otros dos oficiales de la Guardia Civil, se explicaba que «el gobierno republicano tenía un solo deseo: disolver la Guardia Civil» ${ }^{57}$. Los autores presentaban todo el período como una campaña continua contra la Guardia Civil, pero la Benemérita, siempre fiel a su apoliticismo, había aceptado todas las reformas a su estructura «con la más absoluta disciplina $»^{58}$. No obstante, señalaban que los cambios "produjeron graves perturbaciones en el funcionamiento de los servicios del Cuerpo ${ }^{59}$. La Guardia Civil permaneció luchando contra la creciente ola de desorden, convirtiéndose en «el Cuerpo que más sangre derramó en favor de la República» ${ }^{60}$. Como consecuencia, la Segunda República era una lección objetiva de los peligros de no valorar adecuadamente la estructura militar de la Guardia Civil y su papel como guardiana del orden público.

Estos historiadores estaban defendiendo esta estructura militar frente a las convocatorias de desmilitarización tanto dentro como fuera del cuerpo. En su interior, un sindicato clandestino estaba surgiendo e incluía la desmilitarización entre sus demandas ${ }^{61}$. Después de que un número de sus oficiales hubiese estado implicado en el intento de golpe de Estado de 1981, el aumento de las críticas externas al cuerpo contra la militarización de la Guardia Civil daba a los defensores de su estructura militar un nuevo sentido de urgencia. Los historiadores fuera de la institución quienes estaban a favor de la desmilitarización empezaron a tener interés en la Guardia Civil como parte de la historia de la militarización del sistema político español ${ }^{62}$. Manuel Ballbé, por ejemplo, argüía en su influyente obra Orden público y militarismo en la España constitucional (1812-1983) que los regímenes constitucionales españoles, a través de la época contemporánea y con la Segunda República incluida, siempre tenían una política militarizada con motivo del mantenimiento del orden público, por ejemplo con la aplicación de la justicia militar a civiles, las frecuentes declaraciones de emergencia, la influencia inapropiada de las fuerzas armadas en la política y la presencia de fuerzas de orden

56. "La Seguridad pública en el periodo constitucional”, REHGC, 15, 1982, 12.

57. "La Seguridad...", op. cit., 122.

58. "Seguridad pública”, loc. cit 135.

59. “Seguridad pública”, loc. cit 132

60. "Seguridad pública”, loc. cit 142.

61. La primera manifestación de la Guardia Civil y de la policía abogando por la desmilitarización, entre otras cosas, se produjo en 1976. D. Palacios Cerezales, "Repressive Legacies and the Democratisation of Iberian Police Systems", South European Studies and Politics, 15, 2010, 437.

62. Blaney, "La historiografía..., op. cit., 33. 
público militarizadas como la Guardia Civil ${ }^{63}$. Según Ballbé, el problema de la militarización de la Guardia Civil fue que esta estructura involucraba la fuerza en la política pretoriana del Ejército y la eximía del control civil, dando lugar a una brutalidad desmesurada. Ballbé concluye que la militarización del mantenimiento del orden público bloqueó la formación de una democracia estable en la España moderna. La conclusión fue que, en su nueva democracia, el país no podía permitirse este error otra vez.

La respuesta de los historiadores dentro de la Guardia Civil a estas críticas de los 80 fue distanciarse de la publicación de artículos de REHGC sobre el pasado más lejano, y centrarse más en la evolución de la Guardia Civil tras la guerra civil. Los escritores de la revista parecía que se habían dado cuenta de que su viejo marco de defensa de la institución estaba obsoleto, pero, como no tenían un nuevo marco para reemplazarlo, dejaron de escribir sobre su historia conjunta. El caso de la Segunda República destacaba especialmente. En los primeros años de la revista, los artículos sobre este período aparecían de un modo regular, pero en la década de los 80 , solo se publicaron dos trabajos dedicados específicamente a este período, ambos de Fernando Rivas, que por aquel entonces ya había ascendido a capitán ${ }^{64}$.

Uno de estos dos artículos, un texto de 1983 dedicado al incidente de Casas Viejas, demostraba que Rivas había cambiado su forma de escribir sobre la Segunda República desde su publicación de 1976 dedicada al Frente Popular, aunque sus opiniones subyacentes acerca del régimen seguían siendo las mismas. Lejos de una denuncia explícita, aseguraba al lector que «desearíamos que nadie nos creyera críticos contra la República. Nada más lejos de nuestro ánimo ${ }^{65}$. Sin embargo, con una larga lista de incidentes de violencia política seguía mostrando la República como un régimen caótico. Rivas explicaba que su objetivo al escribir el artículo era defender el honor de la Guardia Civil, en esa ocasión contra los relatos que se acababan de publicar sobre Casas Viejas y que se basaban en los vaporosos recuerdos de testigos oculares «cuya memoria forzosamente ha de estar influenciada por acontecimientos posteriores ${ }^{66}$. Sin duda, se refería al libro del antropólogo Jerome Mintz Los anarquistas de Casas Viejas, publicado el año anterior, que presentaba de un modo poco favorecedor la participación de la Guardia Civil en el incidente, a partir de entrevistas con los anarquistas que todavía vivían en la ciudad ${ }^{67}$. Para Rivas, la culpa de la masacre de Casas Viejas era de la Guardia de Asalto, otra fuerza policial militarizada controlada por la República; mientras que «la Guardia Civil, también, en Casas Viejas, ejerció su alta misión de colocar en el centro de aquellas dos antagónicas Españas la sangre y el heroísmo de sus hombres, sin más premio que

63. M. Ballbé, Orden público y militarismo en la España constitucional (1812-1983), Madrid, 1985.

64. F. Rivas, "Rebeldía y represión en Casas Viejas", REHGC, 16, 1983, 125-58, F. Rivas Gómez, "El entierro del Alférez de los Reyes y su trascendencia histórica”, REHGC, 20, 1987, 141-78. También hubo un silencio respecto a la Segunda República en la sociedad española en general durante esta etapa, por el temor a que rememorar el fracaso del último intento de instaurar la democracia en España socavase el esfuerzo del país por dejar atrás la dictadura. Humlebæk, "La memoria...”, op. cit., 161.

65. Rivas, "Rebeldía...”, op. cit., 125.

66. Rivas, "Rebeldía..., op. cit., 134.

67. J. Mintz, The Anarchist of Casas Viejas, Chicago, 1982. 
la pura satisfacción del deber cumplido» ${ }^{68}$. Tuvo un cuidado especial para disociar la Guardia Civil del capitán de la Guardia de Asalto Manuel Rojas Feijespán, quien supuestamente dio la orden de disparar contra los catorce prisioneros desarmados que fueron asesinados. Rivas recordaba al lector que «a un Cuerpo o colectividad no se le puede condenar por la actuación de uno de sus miembros, como tantas veces se ha dicho» ${ }^{69}$. Las críticas a la República ya no podían ser el centro de su escritura, pero todavía mantenía el objetivo de evitar cualquier mancha en el honor de la Guardia Civil.

Cuando publicó los siete volúmenes de su Historia de la Guardia Civil, entre 1983 y 1985, Francisco Aguado Sánchez, entonces general de brigada, también abandonó el lenguaje franquista, aunque mantuvo su concepción de la Segunda República como un tiempo de $\operatorname{caos}^{70}$. Representaba una Guardia Civil siempre a la defensiva contra un flujo constante de ataques, y reunió una notable colección de ellos. También entraba en detalle sobre los cambios de organización de la Guardia Civil, un aspecto de especial interés para él ${ }^{71}$. El autor de la introducción al conjunto enciclopédico, el Director General de la Guardia Civil, José Luis Aramburu Topete, se lamentaba de la falta de familiaridad de la opinión pública con la historia del cuerpo $^{72}$. Sin embargo, el contenido del conjunto especializado y extremadamente detallado, así como las ilustraciones en color de cada volumen y la cubierta lujosa, sugieren que la Historia de la Guardia Civil era un objeto de coleccionistas, de precio elevado y destinado a una pequeña audiencia de guardias civiles y aficionados a la historia militar. Aguado Sánchez estaba defendiendo las tradiciones de la Guardia Civil al escribir su primera historia definitiva, pero lo hacía para un público interno y no para el público en general, en un momento en que había facciones dentro de la Guardia Civil que criticaban su estructura militar y su viejo énfasis en el orden público.

Doce años después escribió La revolución de octubre de 1934, donde Aguado Sánchez todavía era bastante crítico con la República aunque ya no la presentaba sometida a las órdenes directas de la Unión Soviética. Describía la Constitución de 1931 como una ley que no era para todos los españoles, la Ley de Defensa de la República como una «especie de ukase medieval, lo más contrario a un sistema de libertades $»^{73}$, y el intento de golpe de Estado de 1932 como «algo en realidad valioso para la República» ${ }^{74}$. Además, continuaba el patrón de pasar de puntillas por las potenciales manchas en el honor del cuerpo. Por ejemplo, convertía la masacre de Arnedo en un ejemplo digno de alabanza de la famosa disciplina de la Guardia Civil. «Se oye una voz enérgica de “¡Fuego!” Los guardias obedecen maquinalmente» ${ }^{75}$. También alababa el éxito del comandante Doval en la captura de fugitivos y de armas tras octubre

68. Rivas, “Rebeldía...”, op. cit., 157-58.

69. Rivas, “Rebeldía...”, op. cit., 139.

70. Fernando Rivas era su documentalista.

71. Ya había publicado dos artículos sobre la organización de la Guardia Civil en la REHGC. F. Aguado Sánchez, “Organización de la Guardia Civil: Desde la fundación hasta la actualidad”, REHGC, 2-3, 1969-70.

72. Aguado Sánchez, La historia... op. cit., I, 12-13.

73. Aguado Sánchez, La historia... op. cit., IV, ix, 266.

74. Aguado Sánchez, La historia ... op. cit., IV, ix.

75. Aguado Sánchez, La historia ... op. cit., IV, 280. 
de 1934 y no mostraba remordimientos por los métodos empleados ${ }^{76}$. «No vamos a pecar de subjetivos, pero sí dejar sentado que a la vista de los acontecimientos cualquier actuación represiva no es precisamente una postura de las llamadas de "guante blanco" $\gg$ ". Al observar a Fernando Condés, el autor, como Rivas antes que él, enfatizaba que el reingreso del capitán en la Guardia Civil todavía no se había completado cuando capturó a Calvo Sotelo ${ }^{78}$. Afirmaba que incluso el 'marxismo' de Condés se debía a las seducciones de su presunta amante, Margarita Nelken, una diputada socialista por la que Aguado Sánchez sentía un rechazo especial $^{79}$. La rebelión de julio de 1936 fue el único acontecimiento sobre el que parecía haber cambiado significativamente de opinión. Así, ya no lo llamaba el «Glorioso Alzamiento», sino que explicaba el inicio de la guerra civil como la ruptura inevitable de las dos Españas irreconciliables ${ }^{80}$.

\section{Una nueva generación (1989-Presente)}

1988 fue el último año de REHGC, que fue sustituida por Cuadernos de la Guardia Civil ${ }^{81}$. El formato de la nueva revista era similar, aunque tenía artículos tanto sobre temas contemporáneos como sobre historia, completando así el alejamiento de un enfoque exclusivamente histórico que REHGC había iniciado en los $70^{82}$. Su final también supuso la llegada de una nueva generación de historiadores de la Guardia Civil que no habían tenido una experiencia personal de la Segunda República y que se habían formado como guardias civiles después de que su institución hubiese asumido que su misión consistía en garantizar la seguridad ciudadana. Durante la década de los 80 , los niveles de educación de los nuevos alistados así como de los oficiales que se unieron a la Guardia Civil aumentaron espectacularmente ${ }^{83}$. Entrar en la Benemérita se convirtió en un proceso muy competitivo, y las academias especiales de la Guardia Civil comenzaron a preparar a los nuevos miembros en técnicas específicas de policía de seguridad ciudadana, destacando el aspecto democrático sobre los valores militares ${ }^{84}$. Diego Palacios Cerezales cree que «esos cambios transformaron su cultura profesional y su

76. Aguado Sánchez, La historia ... op. cit., V, 117-18.

77. Aguado Sánchez, La historia ... op. cit., V, 117.

78. Aguado Sánchez, La historia ... op. cit., V, 172-73.

79. Aguado Sánchez, La historia ... op. cit., V, 173. Otros comentarios despectivos sobre Nelken en Aguado Sánchez, La historia... op. cit., IV, 173-74 y Aguado Sánchez, La revolución... op. cit., 353, donde anota que «Los "salones" de la Nelken sirvieron de pretexto, sin duda, para captar elementos de las Fuerzas Armadas propensos a deshonrarse».

80. Aguado Sánchez, La historia ... op. cit., V, 175-76 y passim.

81. Blaney, "la historiografía...", op. cit., 33.

82. Guardia Civil también tiene una columna dedicada con frecuencia a la historia, pero cuyos artículos son demasiado cortos para revelar mucho sobre los cambios de perspectiva de los historiadores de la Guardia Civil en la Segunda República; por lo tanto, no se consideran aquí.

83. D. López Garrido, El aparato policial en España: Historia, sociología e ideología, Barcelona, 1987, 123-24.

84. Hudson, "Democracy...", op. cit., 61, López Corral, La Guardia... op. cit., 465-66, Palacios Cerezales, "Repressive...", op. cit., 440. 
imagen ${ }^{85}$, y Robert C. Hudson escribió en 1988 que «la sensación general en el cuartel era que había habido una aceptación total del poder constitucional por la fuerza» ${ }^{86}$. La democracia también transformó la manera de escribir de los guardias civiles acerca de su historia. A medida que la Guardia Civil en su conjunto se centró más en la protección y el compromiso con la ciudadanía, en lugar de esforzarse por permanecer distante y aislada, los historiadores hicieron lo mismo, intentando hacer su trabajo más atractivo para audiencias académicas y populares, además de las clásicas internas ${ }^{87}$. A pesar de que los guardias civiles siempre han estado preocupados por su imagen pública como una parte fundamental del mantenimiento de su honor, parecían darse cuenta en ese momento de que su falta de publicaciones en los medios de comunicación convencionales demostraba que no habían tenido el control de su propia imagen ${ }^{88}$. Resulta revelador que en el primer número de Cuadernos de la Guardia Civil, su Consejo de redacción afirmase que esta publicación nacía «con el único límite del rigor intelectual y el respeto de los principios democráticos» y que una de sus metas sería «acercarse a centros de la cultura y universitarios» ${ }^{89}$.

Esta nueva generación de historiadores de la Guardia Civil todavía se sentía en la necesidad de defender el honor de su institución, pero ya no hacía ningún esfuerzo por demonizar a la República. Destacar los servicios de la Guardia Civil a la ciudadanía, en lugar de su defensa del orden público, se convierte en la clave para documentar el honor que se ha ganado ${ }^{90}$. Al no tener que hacer ese retrato negativo de la Segunda República, la nueva generación enfatiza más que nunca la tradición de neutralidad política de la Guardia Civil. Glorificar su apoliticismo también justifica implícitamente la estructura militar permanente de la institución, ya que, como explicaba el teniente general del Ejército del Aire, Ramón Salas Larrazábal, en Cuardernos de la Guardia Civil, «su vinculación al Ejército... le imprimieron un carácter nacional superador de todo tipo de partidismo» ${ }^{91}$. La vieja meta de enumerar

85. Palacios Cerezales, “Repressive..., op. cit., 440.

86. Hudson, "Democracy..., op. cit., 60.

87. Por ejemplo, Alberto Rico Sánchez, miembro de la Guardia Civil, publicó un artículo en un número de 2007 de Ayer, revista líder de la historia contemporánea de España, en el que afirmaba que durante la Segunda República, los guardias civiles "nunca fueron bien recompensados económicamente, aunque fuesen asesinados por insurgentes de todo signo político". Si bien el argumento de Rico se construye a partir de una cantidad impresionante de datos que reocoge en diversas tablas, sigue apuntando que la Guardia Civil cumplió su deber fiel y desinteresadamente a pesar de la ingratitud de la República. A. Rico Sánchez, "Retribuciones de la Guardia Civil. 1931-1936", Ayer, La extrema derecha en la España contemporánea, 2008, 267.

88. C. A. Capa Gil, M. Alamo Andrés y L.M. Torres Chico, Los Guardias Civiles en la prensa española durante la Democracia (1978-2008): Modernidad y tradición de un cuerpo policial, Valencia, 2009, 114.

89. Apuntado por el Consejo de redacción al principio del primer número de Cuadernos de la Guardia Civil, 1989.

90. Los artículos F. Aguado Sánchez, "Revolución de octubre”, en La guerra y la paz: cincuenta años después. Madrid, 1990 y R. Salas Larrazábal, "La Guardia Civil en la II República”, Cuadernos de la Guardia Civil, 1990, 37-45 no siguen este patrón, pero sus autores pertenecen a la generación anterior.

91. Salas Larrazábal, “La Guardia...”, op. cit., 37. 
incidentes en los que habían participado los guardias civiles, construyendo una especie de hoja de servicios de la Guardia Civil también se mantiene. Aunque no se detenían demasiado en las faltas que pudiesen aparecer, tampoco tenían la necesidad de justificarlas a toda costa, como sucedía en la etapa anterior. Incluso hacen el esfuerzo de recoger voces opuestas a la Guardia Civil.

Dos de los más destacados historiadores de esta nueva generación, Miguel López Corral y Agustín Pulido Pérez, se han involucrado, a diferencia de sus predecesores, en el mundo de la historia académica y divulgativa ${ }^{92}$. López Corral, ahora comandante, se doctoró en Derecho e Historia en la Universidad Complutense de Madrid en 2002. Además de ser oficial de la Guardia Civil, ha impartido clases en diversas academias de policía dentro y fuera de España, y fue profesor de Historia de las Relaciones Internacionales en el Instituto de Estudios Universitarios Duque de Ahumada, vinculado a la Universidad Carlos III de Madrid ${ }^{93}$. Del mismo modo, Pulido Pérez presentó su tesis en la Universidad Nacional de Educación a Distancia en 2012. También es educador en la Academia de Guardias y Suboficiales de la Guardia Civil. Para demostrar su esfuerzo de ser receptivos con otros puntos de vista, ambos han tenido a estudiosos críticos de la Guardia Civil en sus tribunales de tesis ${ }^{94}$.

López Corral comenzó a escribir sobre historia en los últimos tiempos de la REHGC, donde Fernando Rivas fue su mentor ${ }^{95}$. López Corral fue quien propuso el cambio de nombre de REHGC a Cuadernos de la Guardia Civil. Concibió una revista que encarnase la nueva visión policial de la Guardia Civil y que «aspirase a convertirse en la Revista de referencia en España sobre seguridad pública y que cumpliese con la misión de formar, analizar y debatir sobre seguridad $»^{96}$. Además, siguió considerando la historia como una parte crítica de la definición de la identidad y la misión de la Guardia Civil. Como explica, defendió «desde el Consejo de Redacción que se creó que se reservasen dos artículos de Cuadernos para temas históricos, y así se hizo mientras yo fui Redactor Jefe» ${ }^{97}$. También escribió sus propios libros. Después de publicar dos libros sobre la Guardia Civil durante el siglo XIX, se dispuso a intentar una hazaña que ningún guardia civil había intentado desde que Francisco Aguado

92. Blaney, “La historiografía...”, op. cit., 33. El coronel Jesús Narciso Núñez Calvo también se ha sumado a la historia divulgativa, escribiendo más de cien artículos para periódicos y revistas de historia militar. Incluso tiene un blog: http://jesusnarcisonunezcalvo.blogspot.com/.

93. Correo electrónico de Miguel López Corral al autor, 18 de noviembre de 2014.

94. López Corral tuvo a Diego López Garrido en su tribunal y Pulido Pérez a Eduardo González Calleja. Para más información, véase la Base de datos de Tesis Doctorales (TESEO),

https://www.educacion.gob.es/teseo/irGestionarConsulta.do.

95. M. López Corral, "Evolución histórica de los derechos humanos del Guardia Civil”, REHGC, 21, 1988, 7-36, López Corral, La Guardia... op. cit., 15. Curiosamente, López Corral y Rivas trabajaron juntos en J. Sanz Múñoz (Coor.), La Guardia Civil española, 1989, donde López Corral escribió el apartado sobre el siglo XIX y Rivas el dedicado al siglo XX. En él, Rivas trata la Segunda República como lo hizo en los trabajos analizados en el epígrafe anterior de este artículo, con un lenguaje moderado y crítico con la República.

96. Correo de Miguel López Corral al autor, 18 de noviembre de 2014.

97. Correo de Miguel López Corral al autor, 18 de noviembre de 2014. 
Sánchez lo hiciese dos décadas antes: escribir una historia general de la Guardia Civil ${ }^{98}$. El enfoque de López Corral difería considerablemente del de su predecesor. En lugar de una obra inabarcable de siete tomos, escribió un solo volumen de un tamaño razonable, que estaba dirigido al público en general. El libro tenía una portada atractiva y se podía encontrar en las principales librerías, tanto de venta física como de venta por Internet, donde ha conseguido excelentes resultados. En la actualidad va por la segunda edición ${ }^{99}$. Aunque él también dedicó la mayor parte de sus páginas a describir cambios organizativos e incidentes de violencia política, los presenta de manera más sucinta y además, también analiza aspectos relacionados con la contratación, la educación y la vida cotidiana de la institución, cuestiones que alguien ajeno al cuerpo podría no tener en cuenta. Su esperanza es que cuanto más se conozca a la Guardia Civil, más será apreciada ${ }^{100}$. El autor hace un seguimiento de los cambios de su imagen pública a lo largo de su historia y responde a las opiniones negativas sobre la institución, aunque la mayor parte de sus fuentes primarias siguen siendo documentos internos de la Guardia Civil. En su opinión, la importancia de escribir su historia no reside solo «en conocer y dar a conocer la historia de la Guardia Civil, sino en que generaciones venideras puedan aprender de los errores - y también de las virtudes» ${ }^{101}$. De hecho, hace algunas críticas a la Guardia Civil, señalando sus viviendas a menudo inadecuadas así como algunos problemas en su formación profesional. A diferencia de la generación anterior, no glorifica a la Guardia Civil como defensora del orden público, destacando, en cambio su apoliticismo y sus labores humanitarias, haciendo hincapié en sus servicios a la ciudadanía ${ }^{102}$. Y también, a diferencia de sus predecesores, cuando enumera las fuentes secundarias cita bibliografía de todo el espectro político, aunque su principal punto de referencia sigue siendo el historiador conservador Ricardo de la Cierva.

Un año antes de la historia general de la Guardia Civil de López Corral, Agustín Pulido Pérez publicó un libro centrado específicamente en la Segunda República, La Guardia Civil ante el Bienio Azañista, 1931/33 ${ }^{103}$. Este trabajo también se dirigía a un público amplio y recibió una subvención de la Dirección General del Libro, Archivos y Bibliotecas del Ministerio de Cultura. Su tema central era, como en el caso de López Corral, el apoliticismo de la Guardia Civil. El autor sostiene que, si bien la polarización entre las dos Españas aumentó durante el primer bienio, la disciplina de hierro de la Benemérita le aseguró el ganarse el respeto de

98. M. López Corral, La Guardia Civil. Nacimiento y consolidación, 1844-1874, Madrid, 1995, M. López Corral, La Guardia Civil en la Restauración (1875-1905). Militarismo contra subversión y terrorismo anarquista, Madrid, 2005.

99. Correo de Miguel López Corral al autor, 18 de noviembre de 2014. El libro es López Corral, La Guardia... op. cit.

100. López Corral, La Guardia ... op. cit., 17, 19.

101. López Corral, La Guardia... op. cit., 15.

102. López Corral, La Guardia ... op. cit., 18.

103. A.M. Pulido Pérez, La Guardia Civil ante el Bienio Azañista, 1931/33, Madrid, 2008. El libro es una adaptación de la primera parte de su tesis, que se ocupa de la Guardia Civil durante toda la Segunda República. A.M. Pulido Pérez, "La Guardia Civil ante la Segunda República", Tesis doctoral, Universidad Nacional de Educación a Distancia, 2011. 
un nuevo gobierno poco favorable a ella ${ }^{104}$. Pulido Pérez combina viejas y nuevas interpretaciones de la Guardia Civil describiendo su misión como una mezcla de «protección de la seguridad ciudadana y la conservación del orden público» ${ }^{105}$. Se muestra dispuesto a conceder que la Guardia Civil utiliza métodos anticuados para lograr estas metas. Así, explica que la lucha de la institución para adaptarse a la cambiante situación de orden público fue resultado del brusco cambio de régimen de 1931 y del fracaso de la República para proporcionarle el apoyo político y financiero adecuado ${ }^{106}$.

El modo en que López Corral y Pulido Pérez tratan los incidentes más destacados de la Segunda República en los que estuvo implicada la Guardia Civil ilustra su esfuerzo por adoptar un tono más neutral que sea aceptable para el público, sin dejar de defender el honor de la institución. En cuanto a Castilblanco, los dos autores adoptan un enfoque que está mucho menos orientado a destacar el sacrificio heroico de los guardias civiles asesinados de lo que sucedía con los trabajos de sus antecesores. Pulido Pérez proporciona dos relatos de la historia. En una versión, la única que López Corral ofrece ${ }^{107}$, es un guardia civil quien inicia la violencia. En la otra, los cuatro muertos simplemente son atacados por la multitud. Pulido Pérez también señala que uno de los guardias civiles «tuvo algún que otro problema por su continua asistencia a la taberna del pueblo» ${ }^{108}$. En cuanto a Arnedo, ambos autores optan de nuevo por no condenar o por excusar las acciones de la Guardia Civil, en lugar de destacar que la situación era caótica y que no está claro lo que sucedió exactamente. Pulido Pérez concluye que la tragedia fue causada por el terrible miedo que sentían los guardias civiles después de Castilblanco, mientras que López Corral culpa a la formación inadecuada de los agentes en el tratamiento de masas ${ }^{109}$. Al describir los sucesos de Casas Viejas, ambos historiadores señalan la heroica defensa de los guardias civiles de su casa-cuartel, sin embargo, Pulido Pérez ni siquiera menciona las ejecuciones que tuvieron lugar después ${ }^{110}$. López Corral lo hace, pero las considera un resultado de «la España inacabada», recordando al lector que «no todos los abusos atribuidos a la Benemérita en sus enfrentamientos con las masas amotinadas fuesen fruto de sus torpezas y mentalidad» ${ }^{11}$. De esta manera, el autor está pidiendo al público que reevalúe sus posibles prejuicios contra la Guardia Civil y que se le permita un mayor respeto. En su apartado sobre la revolución de octubre de 1934, López Corral, por supuesto, no se refiere a ella como una revolución roja, pero se muestra de acuer-

104. Pulido Pérez, La Guardia... op. cit., 9-10, 12.

105. Pulido Pérez, La Guardia... op. cit., 12.

106. Pulido Pérez, La Guardia... op. cit., 12, 15-16.

107. López Corral, La Guardia... op. cit., 303. El comandante de la Guardia Civil José Luis Ulla Rega también cuenta esta versión en J.L. Ulla Rega, "La Guardia Civil en la Segunda República (1931-1936)", Cuadernos de la Guardia Civil, 1994, 126.

108. Pulido Pérez, La Guardia... op. cit., 102.

109. Pulido Pérez, La Guardia... op. cit., 107-08. La misma explicación aparece en Ulla Rega, "La Guardia..., op. cit., 127 y Salas Larrazábal, “La Guardia..., op. cit., 38, López Corral, La Guardia... op. cit., 307-08.

110. López Corral, La Guardia... op. cit., 322, Pulido Pérez, Guardia... op. cit., 174-75.

111. López Corral, La Guardia... op. cit., 323-24. 
do con el argumento del defensor del régimen franquista, Pío Moa, de que esta fue la primera batalla de la Guerra Civil ${ }^{112}$. Describe a Doval como un comandante que excedió su mando judicial, especialmente con sus detenciones arbitrarias y torturas, a pesar de que cumplió su misión con bastante éxito ${ }^{113}$. Tampoco López Corral retrata el Frente Popular como una revolución roja en espiral creciente y fuera de control, aunque argumenta que la Guardia Civil tenía buenas razones para recurrir contra el gobierno, y repite la afirmación de Ricardo de la Cierva de que tras el asesinato de la Guardia de Asalto de izquierda, teniente José del Castillo, vengado con la muerte de Calvo Sotelo, «no es posible la paz» ${ }^{114}$.

Una nueva generación de historiadores fuera de la Guardia Civil también ha intentado tener una visión más equilibrada de la institución en contraste con las perspectivas polarizadas de la década de 1980, aunque estas nuevas perspectivas son igualmente polémicas. Gerald Blaney cree que los historiadores de la Guardia Civil así como los académicos como Manuel Ballbé ponen demasiado énfasis en la estructura militar de la Guardia Civil en vez de estudiar la institución como una fuerza policial con una agenda política ${ }^{115}$. Blaney defiende que los guardias civiles durante la Segunda República se veían a sí mismos como policías siendo su misión el mantenimiento del orden público de una manera políticamente neutral. Sin embargo, pensaban que el mantenimiento del orden era más importante que su lealtad al gobierno constituido - una actitud que eventualmente provocó a muchos a ponerse en contra de la República durante la guerra civil- ${ }^{116}$. Eduardo González Calleja, mientras que considera a Blaney ligeramente indulgente con la Guardia Civil, también escribe que no era la estructura militar per se la que hizo la institución tan violenta durante la Segunda República, sino la obsesión del estado con el mantenimiento del orden público ${ }^{117}$.

No todos los historiadores están de acuerdo en que se debe encontrar una posición de compromiso entre los detractores y defensores de la Guardia Civil. Por un lado, Chris Ealham en una reseña califica uno de los artículos de Blaney como otra apología de la Guardia Civil. En su opinión, Blaney toma una institución que es «considerada por la mayoría como anti-democrática» $\mathrm{y}$ «menosprecia su papel como fuerza de represión». ${ }^{118}$ Por otro lado, Fernando del Rey recientemente retomó el viejo argumento de que quizás los mismos guardias

112. López Corral, La Guardia... op. cit., 330, P. Moa, Los orígenes de la Guerra Civil Española, Madrid, 1999, P. Moa, El derrumbe de la Segunda República y la Guerra Civil, Madrid, 2009.

113. López Corral, La Guardia... op. cit., 333-34.

114. López Corral, La Guardia... op. cit., 349.

115. G. Blaney, Jr., "The Civil Guard and the Spanish Second Republic 1931-1936”, tesis doctoral, $2007,3$. Se puede encontrar la crítica completa de Blaney de las ideas de Ballbé en Blaney, "La historiografía..., op. cit.

116. G. Blaney, Jr., "Between Order and Loyalty: the Civil Guard and the Spanish Second Republic, 19311936," en G. Oram, (Ed.) Conflict and Legality: Policing mid-twentieth century Europe, London, 2003, 42-43.

117. González Calleja, En nombre... op. cit., 92.

118. C. Ealham, “The Emperor's New Clothes: 'Objectivity’ and Revisionism in Spanish History,” Journal of Contemporary History, 48, 2013, 199. Blaney responde que "nuevas investigaciones sobre este tema han sido contestadas con insultos personales y distorsiones descaradas de sus resultados en vez de diálogo serio con sus resultados". G. Blaney, Jr., "Violence, Continuity, and the Spanish State: Some Considerations", Journal of Contemporary History 51, 2016, 416. 
civiles fueron violentos durante la Segunda República debido a las órdenes que seguían ${ }^{119}$. Al mismo tiempo, Juan Blázquez Miguel ha resucitado una estrategia de los historiadores de la Guardia Civil aún más antigua, la de enumerar cada instancia de violencia política bajo la Segunda República para demostrar que la época fue un tiempo de caos ${ }^{120}$. Sin embargo, Blázquez Miguel ha sido criticado incluso por Fernando del Rey debido a errores y falta de una metodología precisa ${ }^{121}$. En otras palabras, mientras que algunos historiadores dentro y fuera de la Guardia Civil han trabajado por adoptar una actitud más moderada con respeto al papel de la institución en la Segunda República, no han logrado establecer un nuevo consenso post-franquista sobre el tema.

\section{Conclusión}

Fue a partir de 1968, cuando los guardias civiles comenzaron a escribir su propia historia y desde entonces hasta el día de hoy, el objetivo principal de estos historiadores ha sido defender el honor de su institución a través de la documentación de los hechos loables que sus miembros han logrado, siempre en respuesta a amenazas percibidas a su honor. Como resultado de sus trabajos, estos historiadores han producido un conjunto de obras que narran con gran detalle y desde una perspectiva interna, la estructura de la institución en su conjunto y las acciones de sus miembros de manera individual. Durante los años finales de la dictadura franquista, la estrategia era catalogar los hechos gloriosos de los guardias civiles a la vez que se explicaba o ignoraba cualquier posible mancha en el honor de la institución.

Mientras que España realizaba la transición al final de los años 70 y 80 a un sistema político más democrático, el objetivo de los historiadores de la Guardia Civil de preservar el honor de su institución se ha mantenido constante. Sin embargo la forma en la que la sociedad española entiende el papel de las fuerzas policiales ha cambiado drásticamente, pasando de considerarlas las encargadas de mantener el orden público a verlas como garantes de la seguridad ciudadana. Los historiadores de la Guardia Civil fueron lentos en adaptar sus narrativas históricas a la mentalidad nueva, pero gradualmente han conseguido eliminar el lenguaje abiertamente franquista de sus escritos. Al final, la Guardia Civil necesitaría una nueva generación de historiadores para adaptarse plenamente a este cambio de perspectiva de la actuación policial, así como la modificación de la forma en la que la institución defiende

119. F. del Rey, "Reflexiones sobre la violencia política en la II República española”, en M. Gutiérrez Sánchez y D. Palacios Cerezales (Eds.), Conflicto político, democracia y dictadura: Portugal y España en la década de 1930, Madrid, 2007, 39-40.

120. J. Blázquez Miguel, España turbulenta: Alteraciones, violencia y sangre durante la II República, Madrid, 2009.

121. F. del Rey Reguillo, "Policies of Exclusion during the Second Republic: A View from the Grass Roots", en M. Álvarez Tardío y F. del Rey Reguillo, The Spanish Second Republic Revisited: From Democratic Hopes to Civil War (1931-1936), Brighton, 2012, 185, f. 18. Para un resumen de las críticas de la obra de Blázquez Miguel, véase E. González Calleja, Cifras cruentas: las víctimas de la violencia sociopolítica en la Segunda República española (1931-1936), Granada, 2015. 
su honor. En lo que se refiere a la Segunda República, la nueva generación ya no se centra en la lucha de la Guardia Civil contra el desorden, sino que insisten de nuevo en el carácter apolítico del cuerpo de servicio al ciudadano. No obstante, el deseo de estos historiadores en defender el honor de la Guardia Civil ha significado mantener el tono de disculpa de sus antecesores y no han adoptado la idea de historiadores fuera de la institución de que las acciones de los guardias civiles durante la Segunda República sí tenían motivaciones políticas.

Traducido por Pilar Mera Costas 